\title{
Supplier's Selection for the Moroccan Textile Sector by Using Performance Measurement System
}

\author{
Mustapha HLYAL ${ }^{1,4}$, Mohamed Tarek CHAHID ${ }^{1}$, Aziz SOULHI ${ }^{3}$, Jamila EL ALAMI ${ }^{2}$ \& Nouredine EL \\ ALAMI $^{1}$ \\ ${ }^{1}$ University Mohammed V-Agdal, Mohammadia School of Engineers, Rabat, Morocco \\ ${ }^{2}$ University Mohammed V-Agdal, Superior School of Technology Sale, Sale, Morocco \\ ${ }^{3}$ National School of Mineral Industry, Rabat, Morocco \\ ${ }^{4}$ Superior School of Textile and Clothing - (ESITH), Casablanca, Morocco \\ Correspondence: Mustapha HLYAL, Higher School of Textile and Clothing Industries, Route d'Eljadida, km 8, \\ BP 7731 - Oulfa, Casablanca, Morocco. Tel: 212-522-234-152/65. Fax: 212-522-231-585. E-mail: \\ hlyal@esith.ac.ma
}

Received: October 3, 2014

Accepted: November 3, $2014 \quad$ Online Published: January 10, 2015

doi:10.5539/mas.v9n3p102

URL: http://dx.doi.org/10.5539/mas.v9n3p102

\begin{abstract}
This paper proposes a model of performance indicators for Moroccan Textile industry subcontractors. First, the study reports, through a PMQ questionnaire, the KPIs used and deemed relevant by a sample of 82 companies. Second, the weight and hierarchy of various indicators are developed using Analytical Hierarchy Process (AHP) to release a formula for calculating the overall performance. The study shows that outsourcers and Moroccan manufacturers consider compliance with the schedule and the competence and versatility of the production system as a priority. The formula for calculating the overall performance also includes other dimensions such as quality and human resource development. This should facilitate the selection of the contractor and make it more objective.
\end{abstract}

Keywords: Global Performance Formula, Key Performance Indicators (KPI), Performance Measurement Questionnaire (PMQ), AHP, Moroccan Textile industry subcontractors

\section{Introduction}

Regardless the field of activity, choosing the right contractor is a strategic decision that impacts most often the financial results of the company and even its future. A favorable supply chain is a competitive advantage for the company and allows it to have a dominant market position (Arbin, 2008).

However, the selection of several subcontractors based on several quantitative and qualitative criteria is not an easy task (Awasthi et al., 2009) and supply chain managers are faced with complex decision environments (AlHarbi, 2001). The subcontractor selection is often viewed as a multi-criteria decision-making. Criteria such as quality, price, delivery, service performance, modern facilities, procurement delivery time, and others that can be tangible or intangible.

In a context of globalised markets, logistics chains are constantly changing and companies are forced to reassess their suppliers regularly to make sure they comply with the exigencies and to continually improve their competitive capacity.

The textile industry is no exception to the rule, in an industry with low added value, effectively choosing its subcontractor directly impacts the cost of the product. It must be flexible, proactive, and responsive, with a competitive cost. To evaluate the performance, manufacturers are content with measuring their financial performance (Safa et al., 2014).

The textile industry is the largest industrial employer in Morocco with over 1,600 companies employing nearly 175,000 people, about $40 \%$ of the national industrial jobs. It also contributes by $24 \%$ to the Moroccan exports of goods and up to $7 \%$ of the national GDP. In 2013, it produced 600 million pieces in subcontracting, co-sourced 300 million, and produced 100 million pieces in finished products (Textiles, 2014).

Performance measurement is important for the Moroccan textile industry which has witnessed under the impact 
of the crisis during these last years, a great change. Despite the fact that the raw materials are often imported, they still attempt to reinforce the shift from selling minutes of production (i.e. subcontracting) to finished products.

Apart from the financial and HR indicators at the ministry of industry and the professional association AMITH, there is no existing model for measuring performance which is developed in the Moroccan textile sector (AMITH, 2013), We propose a method of systematic scoring all key performance indicators (KPI) and a measurement model that takes into account the main characteristics of the sector. This model can be used by the customer for the selection of subcontractor and may also allow contractors to understand the factors of progress and serve as a tool for continuous improvement.

Firstly, we do a review of literature. Secondly, we explain the definitions and tools for PMS model and then describe the process to develop a framework for performance measurement. Finally, we present a complete example by evaluating five subcontractors which operate in the same sub-sector using the model developed with the results, analysis and conclusions.

\subsection{System Performance Measurement}

The performance measure is a requirement in the management process and therefore it is an important area of research in the industrial and academic circles which invest considerably in human resources and materials (Aracioğlu et al., 2013).

Eccles highlights the significance of the change in the eyes of performance manager who is no longer satisfied with the short-term effectiveness of the financial measures and seeks a broader set of measures to evaluate the performance and sustainability term. Managers find that financial measures make the determination of the past are no longer valid for assessing long-term and overall performance (Eccles, 1991).

The word measurement suggests that the performance measurement system should be balanced; which means it should include indicators necessary and sufficient for decision making rather than pulling all the contours of performance (Micheli and Husband, 2014).

Any system for measuring the performance given (PMS) should provide an improvement in internal processes, help companies better understand customer needs and facilitate the implementation of the strategic management system. The result should be giving improved operational efficiency and overall effectiveness of the company (Berrah and Foulloy, 2013).

The performance of the manufacturing system (cost, quality, delivery and flexibility ...) is determined by the configuration of equipment, manpower, data flows, processes and technology. This configuration gives competitive advantage (Nudurupati et al., 2011).

Braz et al. suggest that good performance measures are quantitative, objective and not subjective. They are simple, understandable, practical, and consistent with appropriate scales and clear, timely objectives. Moreover, their multidimensionality defines the inputs and outputs of the important processes (Braz et al., 2011).

PMS requires more management tools performance structural and procedural framework (Folan and Browne, 2005). According to Neely et al., to facilitate the design of PMS it is necessary to answer clearly the following questions: what should we measure? How do we measure and how do we collect the data? How to reduce the gap between the indicators and measures (Neely et al., 1996)?

Folan and Browne proposed that the measure should be: concrete, closer to the customer, supported by management, and engage human resources in the progress (Folan and Browne, 2005).

Melnyk et al. gives the following definitions: Performance Measurement (PM) is the tool used to measure the effectiveness of the work; therefore, a measure of performance is both quantifiable and verifiable and must have three pillars (Melnyk et al., 2013):

- A performance measure that quantifies what happens.

- A target performance indicates what is considered high and low performance and management support.

- The results give the assurance of being below or above the target.

The absence of one of these elements reduces its effectiveness.

On one hand, the main goal is to transform PMS measurement data into information to assess the effectiveness and efficiency of the action. It is indeed the goal setting, the collection, analysis and interpretation of performance measures. On the other hand, the system should function as a thermostat so that the process is designed to assess the inequality between the actual result and the target in order to identify sources of 
dysfunction and induce actions (Melnyk et al., 2013).

Therefore, two types of expressions of performance are involved in PMS: basic expressions that identify the degrees reached in different objectives, and the aggregate expressions that are a synthesis of performance in terms of overall objectives. Aggregate expressions define the priorities of the strategy and give the choice of these two scenarios based on their expressions of basic performance (Clivillé et al., 2007).

However, Berrah and Foulloy showed that PMS usually cover the following key points (Berrah and Foulloy, 2013):

- The definition of the area concerned with the PMS.

- Expression of decomposition links between strategic objectives and basic objectives.

- Definition of how the representations associated is expressed.

- Choice of the aggregation tools used to obtain expression of the overall performance.

\subsection{The Selection of Supplier}

Examples of literature on supplier's selection are multiple. In the sixties, researchers have begun to define a multitude of criteria, without giving an order of preference, allowing to adapt the approach for selecting the particular situations. A few years later, methods of partner selection and prioritization criteria have emerged to obtain a clearer choice of partners.

(Dickson, 1966) proposes 23 evaluation criteria and demonstrates through his empirical study that the most important factors in evaluating suppliers remain the quality and skills, followed by other criteria that relate directly to the product (delivery, warranty, price). The rest of the criteria is of low or medium importance and generally relates to services and procedures performed by suppliers.

(Weber et al., 1991) basing their study on articles published between 1966 and 1990, they showed that the criteria set out by Dickson are studied in most items; only their importance has changed. The authors observed that the price, delivery, quality, production capacity and geographic location are the criteria most often treated in the literature.

Based in our scholar research, we complete the work of Weber by other articles published until 2010; table 1 shows the major criteria for selecting partners, the numbers indicate the priority for the criterion.

Table 1. Criteria for selecting partners

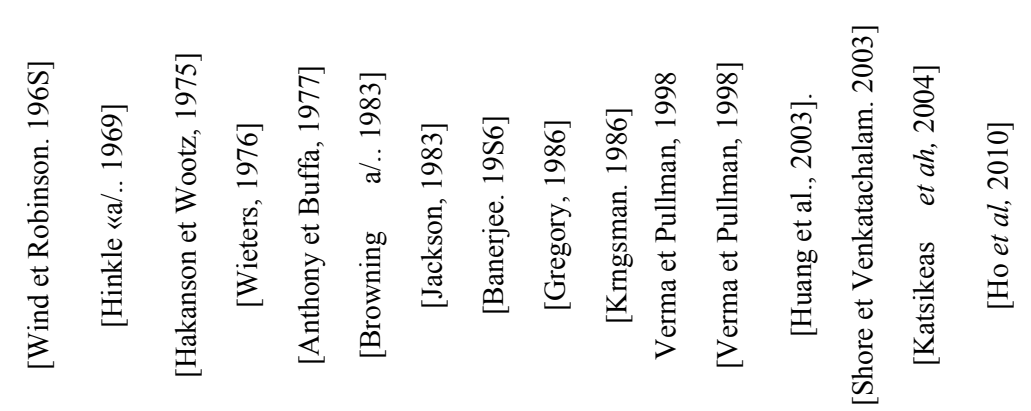

\begin{tabular}{|c|c|c|c|c|c|c|c|c|c|c|c|c|c|c|c|}
\hline Quality & 1 & 1 & 2 & & & & 1 & & 1 & & 1 & 1 & 6 & & 1 \\
\hline Shipping & 2 & 2 & & & 1 & 1 & 2 & 1 & 2 & & 3 & 3 & & & 2 \\
\hline Net Price & 3 & 3 & 1 & & 3 & 2 & & 3 & 5 & 1 & 5 & 2 & 1 & 2 & 3 \\
\hline Reputation and industrial positions & 4 & & & 4 & & & & & 8 & & & & & & \\
\hline Geographical Location & 5 & & 3 & 8 & & & 3 & & 10 & & & & & & \\
\hline Reciprocal agreements & 6 & & & & & & & & & & & & & & \\
\hline Technological capacity & 7 & 4 & & 2 & & 3 & & & & & & & & 4 & \\
\hline Communication systems & 8 & & & & & & & & & & & & & & \\
\hline Purchasing & 9 & 5 & 5 & & 2 & 5 & & 2 & 11 & 2 & & & & & \\
\hline Capacite and facilitates production & & & 4 & 1 & & 4 & & & 4 & & & & & & \\
\hline Financial position, & & & & 3 & & & & & & & & & 2 & & \\
\hline Internal organization & & & & 5 & & & & & 9 & & & & & & \\
\hline Operations Control & & & & 6 & & & & & & & & & & & \\
\hline
\end{tabular}




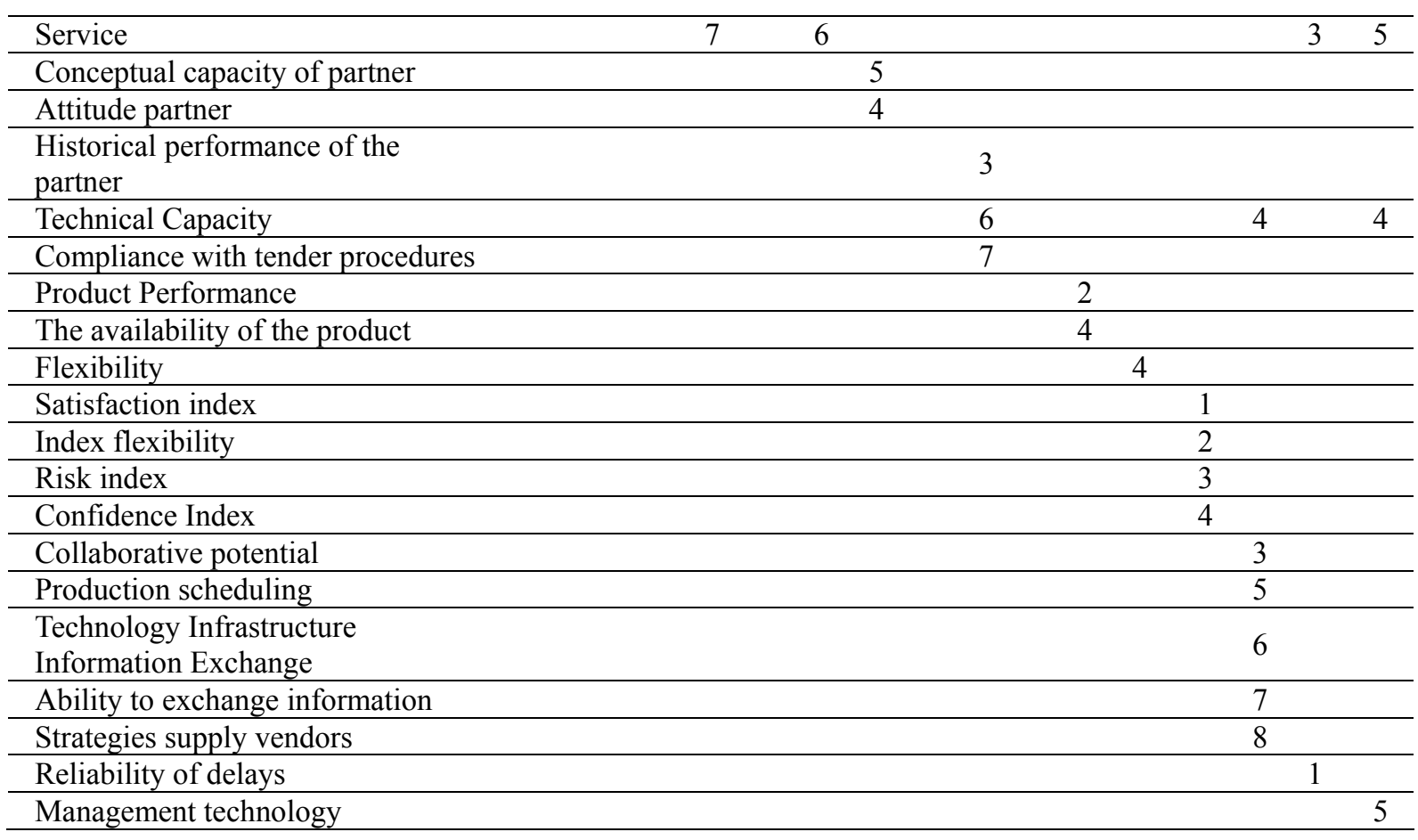

Vonderembse et al. conducted a survey of 268 companies and found that quality, product performance, reliability of delivery, product availability; cost and time are the most frequently used criteria. Also, they concluded that the performance and product quality are the two determinants for companies using or not the concept of JIT criteria. Finally, the authors say companies have a tendency to reduce the number of suppliers and creating strategic partnerships (Vonderembse et al., 1995).

Verma and Pullman initiated a study of 323 companies in the metal industry. They showed that vendor evaluation is mainly based on four criteria: quality, price, delivery and flexibility. Also, they noticed that the quality is the most important criterion (Verma \& Pullman, 1998).

Huang et al. presented the study of a new model of customer-supplier relationships, with a particular interest in methods of new product development. This model includes the following four types of distinct indices: Satisfaction Index (SI), Flexibility Index (FI), Risk Index (RI) and Confidence Index (CI) (Huang et al., 2003).

Huang \& Keskar propose a methodology for selection with a library of 101 criteria. However, faced with a selection problem, the user is not experienced in the method, made a choice of criteria that is rarely (Huang \& Keskar, 2007).

In practice, to choose their suppliers, companies take too match criteria into consideration and invest considerably in the process, human's resources for each criteria, or more often intuitively choose their partners and/or because of their experience. This choice does not always take into account the various factors that influence the success of the cooperation.

\subsection{The Use of KPI}

Key Performance Indicators (KPIs) represent a set of measures focusing on those kinds of organizational performance that are most relevant to the effectiveness of current and future design of the organization or key success factors (KSF) (Parmenter, 2010).

To determine the extent of their performance, companies formulate key performance indicators (KPI) (eg, number of customers, costs) that are considered essential, expressive enough and representative enough of the objectives of the company (Popova and Sharpanskykh, 2011). Systems performance measurement based on the KPIs are linked to the strategy of the organization (Franco-Santos et al., 2012).

PMS defines the objectives arising from the strategy. The different measures collected by the KPIs notify if the goals they are connected to are being reached or not, according to an ascending process (Rodriguez et al., 2009).

Popova and Sharpanskykh describe a method to establish a link between the key performance indicators and targets; they introduce the notion of "performance level" or pattern of goal. The performance of an organization 
can be assessed by estimating the (level of) satisfaction of its objectives (Popova and Sharpanskykh, 2011).

Each KPI has its individual settings, so we need to introduce proportionality the significance of these parameters. Sets of performance should ideally be defined without any unit to ensure proportionality. The measured values are consistent for the service (Lauras et al., 2010).

According to Clivelle et al., proportionality and meanings are intended to improve the consistency of information and take other expressions aggregated from individual performances easier decision (Clivillé et al., 2007). In addition, this development must be understood as an effort to coordinate and not a design effort (Lohman et al., 2004).

\subsection{Using $P M Q$}

Performance Measurement Questionnaire (PMQ) helps to identify areas for improvement of the business and create a plan of correction. It provides a method to identify areas for improvement and identify criteria for measuring performance (Ghalayini et al., 1997) (Chahid et al. 2014).

It is used to link the guidelines and success factors for measures of performance. Questionnaire is distributed to senior management, management of the factory, and the leaders of the team process improvement. Leaders of factory management and team process improvement are integrated to ensure that the needs of each particular plant are met (Ghalayini et al., 1997).

Once the results of the PMQ were indexed, interpretation of results is conducted jointly with the managers of the company (Ghalayini et al., 1997).

The questionnaire has three components:

1. What are the business leaders to ask?

2. What is the priority for the progress in long term and what is the relevance of existing indicators?

3. What are the actual goals and measurements?

\subsection{Using AHP}

The AHP method is the main tool used by researchers and managers of multi-criteria decision making. Areas of using AHP are planning, choosing the best scenarios, resource management (Vaidya and Kumar, 2006). AHP can mix different types of data in the configuration of multi-level decision for a complete visualization project (Hernandez-Matias et al., 2008).

In literature, more than 2000 applications of AHP were counted; they are used in solving multi-criteria problems with qualitative and quantitative aspects (Subramanian \& Ramanathan, 2012).

The AHP also allows aggregation of the expression of performance. Based on ratio scales that are made from human expertise is a complicated task in an industrial context where performance is mainly on (Berrah \& Clivillé 2007a).

He chose the path of adjustment depending on the perceived magnitude of the user performance outlook. On the other hand, measuring the overall performance depends on the policy priorities of performance and proposed by managers (Grigoroudis et al., 2012).

The weighted mean, which is the most recurrent conciliation aggregation operator, is commonly used to get the overall performance (Clivelle et al., 2006).

\subsection{QMPMS Model}

The quantitative model of performance measurement system (QMPMS) provides an expression for the performance to quantify the scope of the overall objective, as the method QMPMS evaluate the overall performance of different strategies and Sensitivity (Bititci, et al., 2001).

According to Suwignjo et al., There are parts in the quantitative model for measuring system performance (QMPMS)

1. Detection of the key success factors (KSF) and their relationship to performance (KPI)

2. Organize factors hierarchically

3. Quantification of the effect of factors on the performance and aggregate them into a single dimensionless unit (overall performance).

In QMPMS, KPIs are recognized with a map of the tree. However, the determination of weighting coefficients is 
based on the method of AHP. The general expression of performance is the aggregation of basic indicators calculated by the weighted arithmetic average operator (WAM) (Suwignjo et al., 2000).

\section{Method}

\subsection{Proposed Method}

To develop our model, the existing performance criteria have been identified and analyzed data collected from a PMQ which collects and selects several key performance indicators. All appropriate key performance indicators (AKPI) were calculated from the key success factors (KSF) that are issued from the compilation of the strategic directions of subcontractors. Then, the weight was attributed to each AKPI by the AHP.

The overall performance (GP) is expressed by the performance of AKPI $\left(\mathrm{P}_{\mathrm{AKPI}}\right)$ with their appropriate weight; $\mathrm{P}_{\mathrm{AKPI}}$ is obtained by comparing the level of the outputs by the value of the percentage formula AKPI measured and the target value. The GP can be used to support decision-making for outsourcers with the subcontractor and it can be used by the contractors themselves to choose new strategies.

To accomplish this research's goal, the subsequent methodology (Figure1) was performed: 1), we obtained the Key Success Factors (KSF) that are the consequence of disaggregation of the major areas of action in Moroccan textile industry. The formulation of KSF objectives correspond to Key Success Performance (KSP) that are established through a set of Key Performance Indicators (KPI), so all KPIs used in those plants were collected; 2) Appropriate Key performance Indicators for all the sector (AKPI) were selected from the Performance Measurement Questionnaire (PMQ); 3) according to the selected indicators (AKPI), a management performance measurement hierarchy was proposed, and the weights of all of the indicators were estimated using an AHP analysis; 4) The quantification by the overall performance is obtained by calculating a weighted mean of all performance expressions associated with the various heterogeneous criteria that are translated into a common reference (achievement level).; 5) the model developed in this study was used and analyzed in Moroccan textile sector.

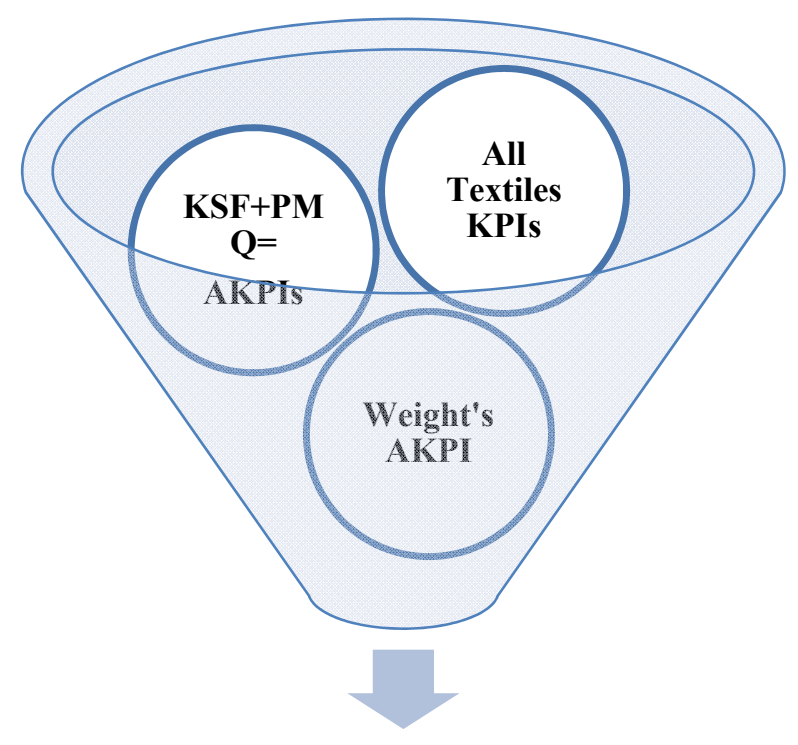

Global Performance Formula

Figure 1. Methodology concept

\subsection{Model Development}

\subsubsection{Matching AKPI}

To reflect the multidimensional aspect of performance, PMQ was used to identify areas for improvement. The PMQ was administered for 110 Moroccan companies in three sectors leather, textiles and clothing, which employs more than 750,000 employees.

A total of 82 responses were collected with a rate of response $75 \%$ as shown in table 2 . 
Table 2. Enterprises interviewed

\begin{tabular}{cc}
\hline Sub sector & Number of companies interviewed \\
\hline Clothing & 54 \\
Textile & 15 \\
\hline
\end{tabular}

The PMQ has allowed to highlight (KSF) considered most important, and adequacy with the strategic objectives of the sample companies. Once defined the KSF, the entire organization is mobilizing to measure and improve it. The PMQ help determine performance criteria that promote improvement. PMQ outputs are used to develop the strategies of organizations, ways the most appropriate progress

For the identification of the KSF that deriving strategic priorities, developing strategic priorities for the 82 subcontractors gave the following areas:

1. The reduction of cost sub-contracting;

2. The improvement of logistics services through the reduction of the period;

3. Development of skills through the improvement of the human resources versatility;

4. Maintaining a favorable climate and accountability of internal staff;

5. The improvement in the level of quality and cost cutting of non-quality;

6. Production capacity.

So to keep the consistency of our approach, we have established a correlation between KSF expressed in our strategic directions with the KPI's that are already selected by companies. Then KPIs are designed to find the right KPIs (AKPI) for overall performance.

Identifying AKPI was equalized by a hierarchical approach in the form of a survey conducted in three parts:

1. What are the company managers to ask?

2. What is the priority for progress in the long term and what is the pertinence of existing indicators?

3. What are the actual goals and measurements?

Therefore, the questionnaires were submitted to entrepreneurs to meet the first requirement PMQ. For the second and third part, priorities for improvement have been identified on the long-term goal of the Moroccan textile sector and checking the adequacy of existing indicators. In the latter, the treatment of PMQ offers AKPI as shown in Table 3.

Table 3. Treatment of KPI in the Moroccan's Textile suppliers, according to PMQ

\begin{tabular}{|c|c|c|c|c|c|c|c|c|c|c|c|c|c|c|c|}
\hline \multirow{2}{*}{\multicolumn{7}{|c|}{$\begin{array}{c}\begin{array}{c}\text { Relevance KPIs existing / } \\
\text { improvement }\end{array} \\
\text { Null } \gg \gg \gg>>>\text { High }\end{array}$}} & \multirow[t]{2}{*}{ KSF } & \multirow{2}{*}{ 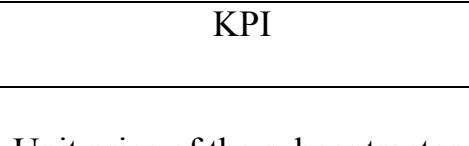 } & \multicolumn{7}{|c|}{$\begin{array}{l}\text { Priority for long term } \\
\text { improvement }\end{array}$} \\
\hline & & & & & & & & & $\mathrm{Nu}$ & & & $>$ & $>\mathrm{H}$ & Iigh & \\
\hline 1 & 2 & 3 & 4 & 5 & 6 & 7 & Cost & Unit price of the subcontractor & 1 & 2 & 3 & 4 & 5 & 6 & 7 \\
\hline 1 & 2 & 3 & 4 & 5 & 6 & 7 & Quality & Quality Cost & 1 & 2 & 3 & 4 & 5 & 6 & 7 \\
\hline 1 & 2 & 3 & 4 & 5 & 6 & 7 & & Rate of non-compliance & 1 & 2 & 3 & 4 & 5 & 6 & 7 \\
\hline 1 & 2 & 3 & 4 & 5 & 6 & 7 & & Rate second choice & 1 & 2 & 3 & 4 & 5 & 6 & 7 \\
\hline 1 & 2 & 3 & 4 & 5 & 6 & 7 & Logistics & Service rate & 1 & 2 & 3 & 4 & 5 & 6 & 7 \\
\hline 1 & 2 & 3 & 4 & 5 & 6 & 7 & & Cycle time & 1 & 2 & 3 & 4 & 5 & 6 & 7 \\
\hline 1 & 2 & 3 & 4 & 5 & 6 & 7 & & Respect the planning & 1 & 2 & 3 & 4 & 5 & 6 & 7 \\
\hline 1 & 2 & 3 & 4 & 5 & 6 & 7 & Production & Production capacity & 1 & 2 & 3 & 4 & 5 & 6 & 7 \\
\hline 1 & 2 & 3 & 4 & 5 & 6 & 7 & & Yield & 1 & 2 & 3 & 4 & 5 & 6 & 7 \\
\hline 1 & 2 & 3 & 4 & 5 & 6 & 7 & Social climate & Absenteeism & 1 & 2 & 3 & 4 & 5 & 6 & 7 \\
\hline 1 & 2 & 3 & 4 & 5 & 6 & 7 & and & Turn over & 1 & 2 & 3 & 4 & 5 & 6 & 7 \\
\hline 1 & 2 & 3 & 4 & 5 & 6 & 7 & & Discipline & 1 & 2 & 3 & 4 & 5 & 6 & 7 \\
\hline 1 & 2 & 3 & 4 & 5 & 6 & 7 & Human & Number of training days & 1 & 2 & 3 & 4 & 5 & 6 & 7 \\
\hline 1 & 2 & 3 & 4 & 5 & 6 & 7 & evelopment & Versatility & 1 & 2 & 3 & 4 & 5 & 6 & 7 \\
\hline
\end{tabular}


In the light of the KPI treatment, we matched the AKPI through the KSF in the table 4:

Table 4. Identification of AKPI for each KSF of Moroccan textile suppliers

\begin{tabular}{|c|c|c|}
\hline KSF & $A K P I$ & Definition \\
\hline Cost & Price subcontractor $(\mathrm{Pr})$ & Price of all or part of the subcontracted product \\
\hline Quality & $\begin{array}{l}\text { Rate of non-compliance } \\
\text { (Rc) }\end{array}$ & $\begin{array}{l}\text { Number of non-compliant section divided by the } \\
\text { total quantity delivered over a period }\end{array}$ \\
\hline Logistics efficiency & Cycle time $(\mathrm{Ct})$ & Delivery Date - date of order \\
\hline Production & Production capacity $(\mathrm{Pc})$ & Production capacity over a period representative \\
\hline Social climate & Turn over (To) & $\begin{array}{l}((\text { Number of recruited + number of departures }) / 2) / \\
\text { actual }\end{array}$ \\
\hline Versatility & Versatility (Vr) & Number of versatile employee / Staff \\
\hline
\end{tabular}

\subsubsection{Weight AKPI}

We have already identified six AKPI (Pr, Rc, Ct; Pc, To, Vr) that are used in the calculation of the overall performance. In fact, each AKPI is coupled with the appropriate weight $\left(r_{1}, r_{2}, r_{3}, r_{4}, r_{5}, r_{6}\right.$ respectively). This association leads us to adopt the AHP method to compare two by two the AKPIs to define their relative importance by expert judgment. Then each AKPI is given absolute importance (weight) on the basis of previous relative importance on a scale ratio, with the constraint that the sum of the weights equals 1 The AHP method is currently the method most commonly used in the industrial application of the aggregated performance expressions. The outranking method compares the different criteria in five levels of importance to overall satisfaction, "equal", "low", "critical", "proven" and "absolute" respectively quantified at 1, 3, 5, 7 and 9 Intermediate values between the two levels are allowed (Cliville, 2004). Experts attribute an intensity number that represents the true preference of each criterion with respect to others. The significance factor of intensity $i$ on factor is equal to $a_{i j}$, and the intensity factor of importance I above $\mathrm{j}$ is equal to $1 / a_{i j}$. If we compare $\mathrm{n}$ factors, we develop a $\mathrm{n} n * n$ matrix A to represent the importance of these factors:

$$
\left(\begin{array}{ccc}
a_{1 n} & \ldots & a_{1 n} \\
\vdots & \ddots & \vdots \\
a_{n 1} & \cdots & a_{n n}
\end{array}\right)=\mathrm{A}
$$

Where $\mathrm{n}$ is the order of the matrix

To determine the weight of each AKPI, we used interviews with experts. In other words, the weight between AKPI was explored on the basis of the response of investigators:

Table 5. Pairwise comparison matrix

\begin{tabular}{ccccccc}
\hline$a_{i j}$ & $\mathrm{Pr}$ & $\mathrm{Rc}$ & $\mathrm{Ct}$ & $\mathrm{Pc}$ & To & $\mathrm{Vr}$ \\
\hline $\operatorname{Pr}$ & 1 & 4 & 5 & 7 & 9 & 2 \\
$\mathrm{Rc}$ & $1 / 4$ & 1 & $1 / 4$ & 6 & 7 & $1 / 2$ \\
$\mathrm{Ct}$ & $1 / 5$ & 4 & 1 & 2 & 3 & 3 \\
$\mathrm{Pc}$ & $1 / 7$ & $1 / 6$ & $1 / 2$ & 1 & 5 & 4 \\
$\mathrm{To}$ & $1 / 9$ & $1 / 7$ & $1 / 3$ & $1 / 5$ & 1 & $1 / 2$ \\
$\mathrm{Vr}$ & $1 / 2$ & 2 & $1 / 3$ & $1 / 4$ & 2 & 1 \\
$\sum_{i, j=1}^{n} a_{i j}$ & 2,20 & 11,31 & 7,42 & 16,45 & 27,00 & 11,00 \\
\hline
\end{tabular}


Table 5 represents the matrix $A_{1}$ as the normalized comparison matrix that is calculated as shown below:

$$
\left(\begin{array}{ccc}
a_{1 n}^{\prime} & \cdots & a_{1 n}^{\prime} \\
\vdots & \ddots & \vdots \\
a_{n 1}^{\prime} & \cdots & a_{n n}^{\prime}
\end{array}\right)=\mathrm{A}_{1} \text { And } a^{\prime}=\frac{a_{i j}}{\sum_{i, j=1}^{n} a_{i j}} \quad \text { for } i, j=1,2, \ldots, n,
$$

Table 6. Matrix A1

\begin{tabular}{ccccccc}
\hline$a_{i j}^{\prime}$ & $\operatorname{Pr}$ & $\mathrm{Rc}$ & $\mathrm{Ct}$ & $\mathrm{Pc}$ & $\mathrm{T}$ & $\mathrm{Vr}$ \\
\hline $\operatorname{Pr}$ & $(1) / 2,20$ & $(4) / 11,31$ & $(5) / 7,42$ & $(7) / 16,45$ & $(9) / 27$ & $(2) / 11$ \\
$\mathrm{Rc}$ & $(1 / 4) / 2,20$ & $(1) / 11,31$ & $(1 / 4) / 7,42$ & $(6) / 16,45$ & $(7) / 27$ & $(1 / 2) / 11$ \\
$\mathrm{Ct}$ & $(1 / 5) / 2,20$ & $(4) / 11,31$ & $(1) / 7,42$ & $(2) / 16,45$ & $(3) / 27$ & $(3) / 11$ \\
$\mathrm{Pc}$ & $(1 / 7) / 2,20$ & $(1 / 6) / 11,31$ & $(1 / 2) / 7,42$ & $(1) / 16,45$ & $(5) / 27$ & $(4) / 11$ \\
$\mathrm{To}$ & $(1 / 9) / 2,20$ & $(1 / 7) / 11,31$ & $(1 / 3) / 7,42$ & $(1 / 5) / 16,45$ & $(1) / 27$ & $(1 / 2) / 11$ \\
$\mathrm{Vr}$ & $(1 / 2) / 2,20$ & $(2) / 11,31$ & $(1 / 3) / 7,42$ & $(1 / 4) / 16,45$ & $(2) / 27$ & $(1) / 11$ \\
\hline
\end{tabular}

The table 6 calculates the eigenvalue and the eigenvector.

$$
\left(\begin{array}{l}
w_{1} \\
w_{2} \\
\vdots \\
w_{n}
\end{array}\right)=w \quad \text { And } \omega \mathrm{l}=\frac{\sum_{i, j=1}^{n} a_{i j}^{\prime}}{n} \quad \text { for } i j=1,2, \ldots, n,
$$

The respective weight of each AKPI (Pr, Rc, Ct, Pc, To, Vr) is given in Table 7:

Table 7. Determination of AKPIs' weight

\begin{tabular}{cccccccccc}
\hline a'ij & Pr & Rc & Ct & Pc & To & Vr & $\sum_{i, j=1}^{n} a_{i j}^{\prime}$ & $\sum_{i, j=1}^{n} a_{i j}^{\prime}$ & Weight (wi) \\
& & & & & & & & & \\
\hline Pr & 0,45 & 0,35 & 0,67 & 0,43 & 0,33 & 0,18 & 2,42 & $(2,42) / 6$ & 0,40 \\
Rc & 0,11 & 0,09 & 0,03 & 0,36 & 0,26 & 0,05 & 0,91 & $(0,91) / 6$ & 0,15 \\
Ct & 0,09 & 0,35 & 0,13 & 0,12 & 0,11 & 0,27 & 1,08 & $(1,08) / 6$ & 0,18 \\
Pc & 0,06 & 0,01 & 0,07 & 0,06 & 0,19 & 0,36 & 0,76 & $(0,76) / 6$ & 0,13 \\
To & 0,05 & 0,01 & 0,04 & 0,01 & 0,04 & 0,05 & 0,20 & $(0,20) / 6$ & 0,03 \\
Vr & 0,23 & 0,18 & 0,04 & 0,02 & 0,07 & 0,09 & 0,63 & $(0,63) / 6$ & 0,10 \\
\hline
\end{tabular}

Figure 2 shows the importance of each weight, in fact, the weight of Price subcontractor (Pr) was the highest with a value 0,40, followed by the weight of Cycle time $(\mathbf{C t})$ with 0,18 . 


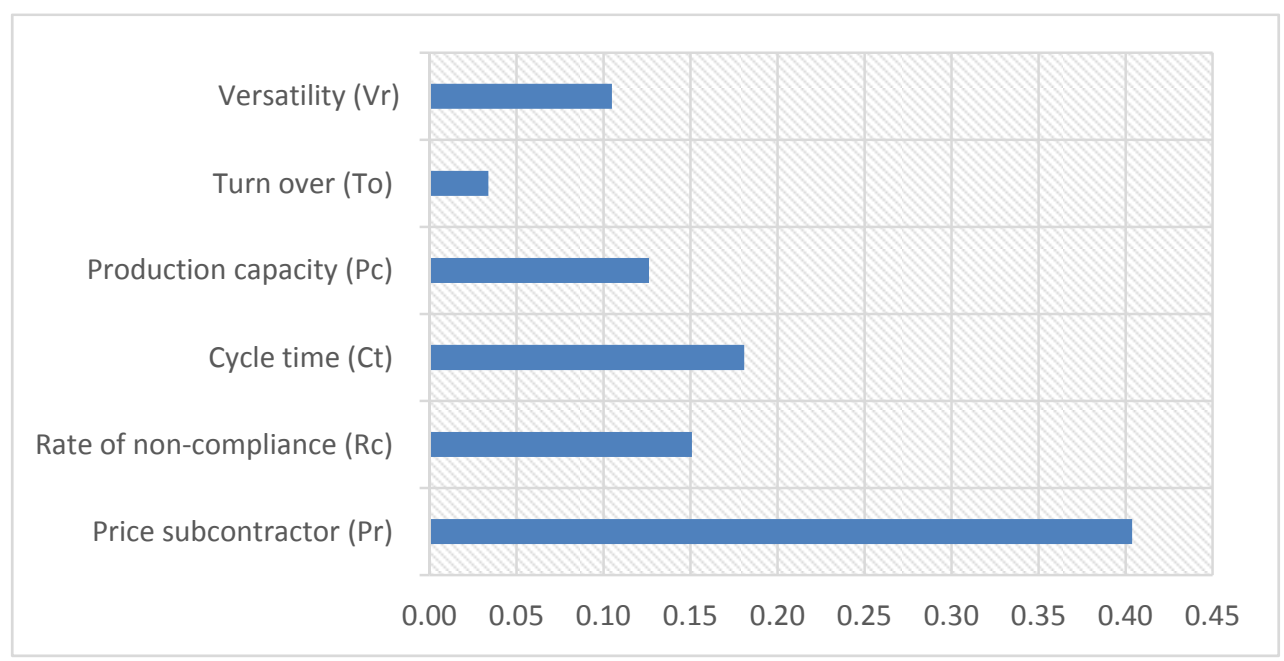

Figure 2. Analysis of weight AKPI

Figure 2 shows that the price of the transaction remains the paramount consideration in the choice of decision monitoring cycle time. The availability of labor; and internal environment are integrated into the overall performance of these subcontractors, but has relatively little impact.

The majority of SME (Small and Medium Enterprises) managers take into account the approximate triangle (cost, quality and time) and which one intuitive choice. Our model shows that there are other key success factor (the social climate and versatility) concerning the logistic qualitative human resource foundation of any progress of any kind whatsoever, or otherwise. These factors should be incorporated into the strategic, tactical and operational management.

\subsubsection{AKPI Estimated Score}

In general, the KPIs are divided into quantitative and qualitative indicators. Represent quantitative performance numbers, even if the qualitative performance indicator should be calculated to measure the performance Thus, each AKPI associated with their estimation methods as shown in Table 4 (Lee et al., 2013).

Table 8. AKPIs calculation methods and AKPIs target values

\begin{tabular}{clc}
\hline AKPI & Definition & Target \\
\hline $\mathrm{Pr}$ & Price subcontractor $(\mathrm{Pr})$ & 30 \\
$\mathrm{Rc}$ & Rate of non-compliance (Rc) & $1,5 \%$ \\
$\mathrm{Ct}$ & Cycle time (Ct) & 7 \\
$\mathrm{Pc}$ & Production capacity $(\mathrm{Pc})$ & 1200 \\
$\mathrm{To}$ & Turn over (To) & $3 \%$ \\
$\mathrm{Vr}$ & Versatility (Vr) & $15 \%$ \\
\hline
\end{tabular}

The overall performance (GP) is expressed through performance AKPI ( $\left.\mathrm{P}_{\mathrm{AKPI}}\right) \mathrm{P}$ is obtained by comparing the performance level (AL) by the value of the formula measured percentage AKPI and the target value. Those AKPI are expressions of satisfaction criteria as the percentage between the current value and the target value for each AKPI. These targets were prepared by investigators for each KPI are shown in Table 8:

$\mathrm{P}_{\mathrm{AKPI}}$ is obtained by matching AL through the table 9 . 
Table 9. Calculating value of $\mathrm{P}_{\mathrm{AKPI}}$

\begin{tabular}{ll}
\hline $\mathrm{P}_{\mathrm{AKPI}}$ Value & AKPI measured \\
\hline 1 & AKPI lower than target above $60 \%$ \\
0,95 & AKPI lower than target $41-60 \%$ \\
0,9 & AKPI lower than target $21-40 \%$ \\
0,85 & AKPI lower than target $6-20 \%$ \\
0,8 & AKPI equivalent to target $+/-5 \%$ \\
0,75 & AKPI higher than target $6-20 \%$ \\
0,7 & AKPI higher than target $21-40 \%$ \\
0,65 & AKPI higher than target $41-60 \%$ \\
0,6 & AKPI higher than target above $60 \%$ \\
\hline
\end{tabular}

The global performance (GP) is expressed in the formula below (Chen, 2008):

$$
G P=100 *\left(\mathrm{P}_{A K P I} * \sum_{i=1}^{6} r_{i}\right)
$$

Therefore, the formula for overall performance of Moroccan Textile suppliers is calculated as follows:

$$
G P=100 *\left(0,40 P_{P r}+0,15 P_{R c}+0,18 P_{C t}+0,13 P_{P c}+0,03 P_{T o}+0,10 P_{V r}\right)
$$

\subsection{Case Study}

To confirm the applicability of the structural formula. We measured the overall performance (GP) of 5 subcontractors $\left(\mathrm{S}_{\mathrm{p} 1}, \mathrm{~S}_{\mathrm{p} 2}, \mathrm{~S}_{\mathrm{p} 3}, \mathrm{~S}_{\mathrm{p} 4}\right.$ and $\left.\mathrm{S}_{\mathrm{p} 5}\right)$ to situate them in relation to the objectives of the sector.

The aim being to select and analyze the key factors for success AKPIs elaborate on the overall rating of " the overall performance " and identify most pertinent progress.

Improvement actions are easily identifiable by the measures (AKPI).

Specifically, Table 10 below shows the GP for each company and the score of each AKPI. Measures the performance of each company on each AKPI are compared to the target values of the sector.

Table 10. Suppliers scores

\begin{tabular}{lcccccc}
\hline & \multicolumn{5}{c}{ Measured value } \\
\hline AKPI & Target & $\mathrm{S}_{\mathrm{p} 1}$ & $\mathrm{~S}_{\mathrm{p} 2}$ & $\mathrm{~S}_{\mathrm{p} 3}$ & $\mathrm{~S}_{\mathrm{p} 4}$ & $\mathrm{~S}_{\mathrm{p} 5}$ \\
Price subcontractor (Pr) & 30 & 40 & 30 & 24 & 35 & 36 \\
Rate of non-compliance (Rc) & $1,5 \%$ & $2,0 \%$ & $1,0 \%$ & $0,9 \%$ & $0,5 \%$ & $1,5 \%$ \\
Cycle time (Ct) & 7 & 8 & 7 & 10 & 10 & 5 \\
Production capacity (Pc) & 1200 & 900 & 1700 & 1500 & 750 & 1200 \\
Turn over (To) & $3 \%$ & $1 \%$ & $0,25 \%$ & $2 \%$ & $2 \%$ & $4 \%$ \\
Versatility (Vr) & $15 \%$ & $15 \%$ & $25 \%$ & $25 \%$ & $10 \%$ & $5 \%$ \\
\hline
\end{tabular}

Table 11. Achievement level "level of satisfaction"

\begin{tabular}{llllll}
\hline & \multicolumn{5}{c}{ Achievement level } \\
\hline AKPI & $\mathrm{S}_{\mathrm{p} 1}$ & $\mathrm{~S}_{\mathrm{p} 2}$ & $\mathrm{~S}_{\mathrm{p} 3}$ & $\mathrm{~S}_{\mathrm{p} 4}$ & $\mathrm{~S}_{\mathrm{p} 5}$ \\
Price subcontractor (Pr) & $-33,33 \%$ & $0,00 \%$ & $20,00 \%$ & $-16,67 \%$ & $-20,00 \%$ \\
Rate of non-compliance (Rc) & $-33,33 \%$ & $33,33 \%$ & $40,00 \%$ & $66,67 \%$ & $0,00 \%$ \\
Cycle time (Ct) & $-14,29 \%$ & $0,00 \%$ & $-42,86 \%$ & $-42,86 \%$ & $28,57 \%$ \\
Production capacity (Pc) & $-25,00 \%$ & $41,67 \%$ & $25,00 \%$ & $-37,50 \%$ & $0,00 \%$ \\
Turn over (To) & $66,67 \%$ & $91,67 \%$ & $33,33 \%$ & $33,33 \%$ & $-16,67 \%$ \\
Versatility (Vr) & $0,00 \%$ & $66,67 \%$ & $66,67 \%$ & $-33,33 \%$ & $-66,67 \%$ \\
\hline
\end{tabular}


Table 12. Performance $\mathrm{P}_{\text {AKPI }}$

\begin{tabular}{lcccccc}
\hline & & & & PAKPI & \\
\hline AKPI & Weight & $\mathrm{S}_{\mathrm{p} 1}$ & $\mathrm{~S}_{\mathrm{p} 2}$ & $\mathrm{~S}_{\mathrm{p} 3}$ & $\mathrm{~S}_{\mathrm{p} 4}$ & $\mathrm{~S}_{\mathrm{p} 5}$ \\
Price subcontractor (Pr) & 0,40 & 0,7 & 0,8 & 0,85 & 0,75 & 0,75 \\
Rate of non-compliance (Rc) & 0,15 & 0,7 & 0,9 & 0,9 & 1 & 0,8 \\
Cycle time (Ct) & 0,18 & 0,75 & 0,8 & 0,65 & 0,65 & 0,9 \\
Production capacity (Pc) & 0,13 & 0,7 & 0,95 & 0,9 & 0,7 & 0,8 \\
Turn over (To) & 0,03 & 1 & 1 & 0,9 & 0,9 & 0,75 \\
Versatility (Vr) & 0,10 & 0,8 & 1 & 1 & 0,7 & 0,6 \\
\hline
\end{tabular}

Table 13. Scores and Global performance (GP)

\begin{tabular}{llllll}
\hline & \multicolumn{5}{c}{ Score } \\
\hline AKPI & $\mathrm{S}_{\mathrm{p} 1}$ & $\mathrm{~S}_{\mathrm{p} 2}$ & $\mathrm{~S}_{\mathrm{p} 3}$ & $\mathrm{~S}_{\mathrm{p} 4}$ & $\mathrm{~S}_{\mathrm{p} 5}$ \\
Price subcontractor (Pr) & $28,26 \%$ & $32,30 \%$ & $34,32 \%$ & $30,28 \%$ & $30,28 \%$ \\
Rate of non-compliance (Rc) & $10,56 \%$ & $13,58 \%$ & $13,58 \%$ & $15,08 \%$ & $12,07 \%$ \\
Cycle time (Ct) & $13,56 \%$ & $14,46 \%$ & $11,75 \%$ & $11,75 \%$ & $16,27 \%$ \\
Production capacity (Pc) & $8,83 \%$ & $11,98 \%$ & $11,35 \%$ & $8,83 \%$ & $10,09 \%$ \\
Turn over (To) & $3,38 \%$ & $3,38 \%$ & $3,04 \%$ & $3,04 \%$ & $2,53 \%$ \\
Versatility (Vr) & $8,38 \%$ & $10,48 \%$ & $10,48 \%$ & $7,34 \%$ & $6,29 \%$ \\
Global Performance (GP) & $72,97 \%$ & $86,17 \%$ & $84,51 \%$ & $76,32 \%$ & $77,52 \%$ \\
\hline
\end{tabular}

\section{Result}

Figure 3 show that the best overall $86 \%$ and $85 \%$ performance are obtained respectively by 2 Subcontractors $\mathrm{S}_{\mathrm{p} 2}$ and $\mathrm{S}_{\mathrm{p} 3}$. The comparison between aforementioned subcontractors prioritizes $\mathrm{S}_{\mathrm{p} 2}(86 \%)$, which have a subcontracting cost more expensive $20 \%$. An intuitive choice of a manager of an SME would probably lean toward the subcontractor $S_{p 3}$ who is more efficient on the cost criterion (Price subcontractor $S_{p 3}=20$ ).

our model select the Subcontractor $\mathrm{S}_{\mathrm{p} 2}$ who have the more efficient global performances with $\mathrm{GP}_{\mathrm{p} 2}=86 \%$. The good result of the $\mathrm{S}_{\mathrm{p} 2}$ is to have a social climate that allows a stable workforce with low turnover by $0.25 \%$ to the professional average and $25 \%$ versatility. The versatility and skill of its workforce also have an impact on optimizing the production cycle.

In practice, the outsourcer can be more interested by the subcontractor $S_{p 5}$ that has exactly the desired capacity (1200) and the shortest Cycle time (5). It can be brought to offer him a technical assistance to improve the versatility and stability of its workforce through continued training. On recalculating the overall $\mathrm{S}_{\mathrm{p} 5}$ performance, with the assumption that there is the possibility to reach the same rank as $S_{p 2}$ on the turnover and versatility. Thereby, overall $\mathrm{S}_{\mathrm{p} 5}$ performance will attain $83 \%$.

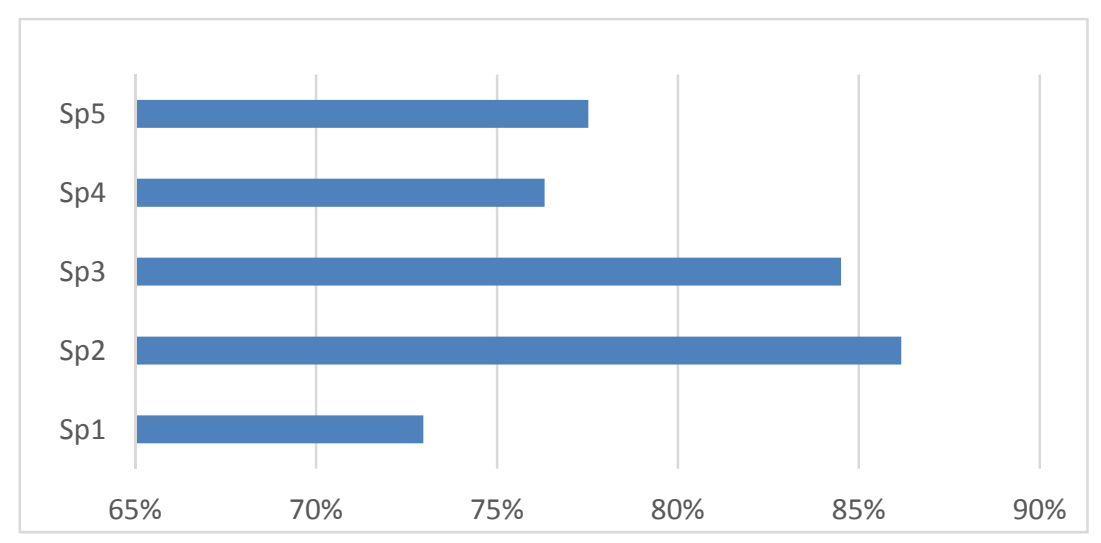

Figure 3. Global performance for 5 subcontractors

The final results analysis shows that the versatility and social climate factors have a positive impact on the 
performance suppliers 'scoring. Therefore, the supplier's strategies should focus on learning factors to improve the performance. It shows that improving the human resource factor has direct impact on all aspects of performance and encourages to take it into account, that focusing can substitute other strategies based on cost.

In this case, the most relevant progress is to choose the fit combination of elementary KPI in order to improve the ranking of the supplier with regard of optimal cost.

\section{Discussions}

In a performance suppliers measurement system a large number of multidimensional factors can affect performance, integrating those multidimensional effects into a single unit can be done through group judgement. It is impossible to have objective measurement and scale system for each different dimension of measurement that can facilitate objective value trade of between different measures.

Our model for the textile industry has applied the PMQ for choosing the right KPIs (AKPI) for the entire Moroccan textile industry, from the results of the interviews with managers and that are coupled with the key success factors. Good practical experiences of using AHP usually enable people to provide accurate judgement.

This model is a contribution to the establishment of a quantitative assessment of performance in the Moroccan textile industry that complies with international standards.

Since the QMPMS using group judgement rather than individual judgement. This will reduce the subjectivity of the judgement. The accuracy of the QMPMS can also be improved through experience.

However, our model gives a correction of the supplier's choice that based on the iron triangle (cost, quality, delay). Following our research, the factors of this choice must take account of other KSF such as the human factors.

The consequences concluded from this research are:

The application of the model based on AHP to weight all appropriate KPI, and the use of the achievement level of each KPIs were beneficial to calculate the overall performance based on elementary indicators which are available in textile industry reports and also easy to collect. This will contribute to an easiest implementation.

The analysis of the PMQ's results shows that the appropriate AKPIs (Pr; Rc; Ct; Pc; To; Vr) are the most pertinent in the expression of supplier's selection. Hence, the Price subcontractor $(\mathrm{Pr})$ and Cycle time $(\mathrm{Ct})$ are most critical AKPI in the global performance.

The analyse of KSF / AKPI showed that the most important factors in the overall performance of Moroccan subcontractors in the textile sector are cost and cycle time, but the development of human skills also has an important impact.

The model presented in this study is a generic method that can be very helpful for Moroccan companies working in the textile sector in order to accomplish strategic, tactical and operational management

\section{Conclusion}

The model given in this paper focuses on one of the pillar of management and continuous improvement (measuring performance). It gives a comprehensive view of pertinent selection of suppliers in the Moroccan textile sector by providing a scoring of their overall performance. The model can be used to identify and select the best manufacturing suppliers, also, it can be used by the suppliers to improve their performance and to find the roots of their weaknesses.

Furthermore, the model incorporate all the areas of improvement paired with the flexibility by combining linear performance parameters in order to assist top management in the selection process.

However, this research does not address the complex and dynamic interrelationships between AKPIs aspects. Thus, for further investigation, it is important to study these aspects.

Also the dynamic nature of the internal and external environment implies that the performance measurement system is dynamic and it changes as the internal and/or external environment changes.

Therefore, the quantitative model, which emerges from the QMPMS approach, has a life cycle and is only valid as long as the internal and external environment remains stable. Any significant change in the external or internal company environment may invalidate the model. So, it is important to recognise these changes as soon as possible so that the quantitative basis of the model is redefined to reflect the true picture.

Future research will be targeted to deal with the dynamic nature of the performance measurement system by building in capabilities to make itself auditing and self-adjusting. 


\section{Acknowledgement}

We would like to thank Mr. Mohamed LAHLOU, President of Inter professional Assistance Council (GIAC) of Textile and clothing sector, and Chairman of the board of the Higher School of Textile and Clothing Industries (ESITH) for his help and support in the realization of this manuscript.

\section{References}

Al-Harbi, K. M. A. S. (2001). Application of the AHP in Project Management. International Journal of Project Management, 19, 19-27. http://dx.doi.org/10.1016/S0263-7863(99)00038-1

Aracıoğlu, B., Ali, E, Z., \& Cemre, C. (2013). Measuring and Evaluating Performance within the Strategic Management Perspective: A Study on Performance Measurement of a Seafood Company. Procedia - Social and Behavioral Sciences, 99, 1026-34. http://dx.doi.org/10.1016/j.sbspro.2013.10.576

Arbin, K. (2008). The Structure of Determinants of Individual Adoption and Use of E-Ordering Systems. Human Systems Management, 27, 143-59. http://dx.doi.org/10.3233/HSM-2008-0676

Awasthi, A., Chauhan, S. S., Goyal, S. K., \& Jean, M. P. (2009). Supplier Selection Problem for a Single Manufacturing Unit under Stochastic Demand. International Journal of Production Economics, 117, 229-33. http://dx.doi.org/10.1016/j.ijpe.2008.10.012

Berrah, L., \& Vincent, C. (2007). Towards an Aggregation Performance Measurement System Model in a Supply Chain Context. Computers in Industry, 58, 709-19. http://dx.doi.org/10.1016/j.compind.2007.05.012

Berrah, L., \& Laurent, F. (2013). Towards a Unified Descriptive Framework for Industrial Objective Declaration and Performance Measurement. Computers in Industry, 64, 650-62. http://dx.doi.org/10.1016/j.compind.2013.03.006

Bititci, U. S., Suwignjo, P., \& Carrie, A. S. (2001). Strategy Management through Quantitative Modelling of Performance Measurement Systems. International Journal of Production Economics, 69, $15-22$. http://dx.doi.org/10.1016/S0925-5273(99)00113-9

Braz, R. G. F., Luiz, F. S., \& Roberto, A. M. (2011). Reviewing and Improving Performance Measurement Systems: An Action Research. International Journal of Production Economics, 133, 751-60. http://dx.doi.org/10.1016/j.ijpe.2011.06.003

Chahid, M. T., Jamila, E. L., Alami, A. S., \& Nouredine, E. L. A. (2014). Performance Measurement Model for Moroccan Automotive Suppliers Using PMQ and AHP, 8, 137-52. http://dx.doi.org/10.5539/mas.v8n6p137

Chen, C. C. (2008). An Objective-Oriented and Product-Line-Based Manufacturing Performance Measurement. International Journal of Production Economics, 112, 380-90. http://dx.doi.org/10.1016/j.ijpe.2007.03.016

CLIVILLE, V. (2004). Systemic Approach and Multicriteria Method for the Definition of Performance Indicators System.

Clivillé, V., Lamia, B., \& Gilles, M. (2007). Quantitative Expression and Aggregation of Performance Measurements Based on the MACBETH Multi-Criteria Method. International Journal of Production Economics, 105, 171-89. http://dx.doi.org/10.1016/j.ijpe.2006.03.002

Dickson, G. W. (1966). An Analysis of Vendor Selection Systems and Decisions. Journal of Purchasing, 2, 5-17. http://dx.doi.org/10.5465/AMBPP.1966.4980919

Eccles, R. G. (1991). The Performance Measurement Manifesto. Harvard Business Review, 69, $131-37$.

Folan, P., Jim, B., \& Harinder, J. (2007). Performance: Its Meaning and Content for Today's Business Research. Computers in Industry, 58, 605-20. http://dx.doi.org/10.1016/j.compind.2007.05.002

Franco-Santos, M., Lorenzo, L., \& Mike, B. (2012). Contemporary Performance Measurement Systems: A Review of Their Consequences and a Framework for Research. Management Accounting Research, 23, 79-119. http://dx.doi.org/10.1016/j.mar.2012.04.001

Ghalayini, A. M., James, S. N., \& Thomas, J. C. (1997). An Integrated Dynamic Performance Measurement System for Improving Manufacturing Competitiveness. International Journal of Production Economics, 48, 207-25. http://dx.doi.org/10.1016/S0925-5273(96)00093-X

Grigoroudis, E., Orfanoudaki, E., \& Zopounidis, C. (2012). Strategic Performance Measurement in a Healthcare Organisation: A Multiple Criteria Approach Based on Balanced Scorecard. Omega, 40, $104-19$. http://dx.doi.org/10.1016/j.omega.2011.04.001

Hernandez-Matias, J. C., Vizan, A., Perez-Garcia, J., \& Rios, J. (2008). An Integrated Modelling Framework to 
Support Manufacturing System Diagnosis for Continuous Improvement. Robotics and Computer-Integrated Manufacturing, 24, 187-99. http://dx.doi.org/10.1016/j.rcim.2006.10.003

Huang, S. H., \& Harshal, K. (2007). Comprehensive and Configurable Metrics for Supplier Selection. International Journal of Production Economics, 105, 510-23. http://dx.doi.org/10.1016/j.ijpe.2006.04.020

Lauras, M., Guillaume, M., \& Didier, G. (2010). Towards a Multi-Dimensional Project Performance Measurement System. Decision Support Systems, 48, 342-53. http://dx.doi.org/10.1016/j.dss.2009.09.002

Lohman, C., Leonard, F., \& Marc, W. (2004). Designing a Performance Measurement System: A Case Study. European Journal of Operational Research, 156, 267-86 http://dx.doi.org/10.1016/S0377-2217(02)00918-9

Melnyk, S. A., Umit, B., Ken, P., Jutta, T., \& Andersen, B. (2013). Is Performance Measurement and Management Fit for the Future? Management Accounting Research, http://dx.doi.org/10.1016/j.mar.2013.07.007

Micheli, P., \& Luca, M. (2014). The Theory and Practice of Performance Measurement. Management Accounting Research, 25, 147-156. http://dx.doi.org/10.1016/j.mar.2013.07.005

Neely, A., John, M., Ken, P., Mike, G., \& Huw, R. (1996). Performance Measurement System Design: Should Process Based Approaches Be Adopted? International Journal of Production Economics, 46-47, 423-431. http://dx.doi.org/10.1016/S0925-5273(96)00080-1

Nudurupati, S. S., Bititci, U. S., Kumar, V., \& Chan, F. T. S. (2011). State of the Art Literature Review on Performance Measurement. Computers \& Industrial Engineering, 60, 279-90. http://dx.doi.org/10.1016/j.cie.2010.11.010

Parmenter, D. (2010). Key Performance Indicators ( KPI ). in Key Performance Indicators ( KPI): Developing , Implementing , and Using Winning KPIs Second Edition, p. 9. http://dx.doi.org/978-0470545157

Popova, V., \& Alexei, S. (2011). Formal Modelling of Organisational Goals Based on Performance Indicators. Data and Knowledge Engineering, 70, 335-64 http://dx.doi.org/10.1016/j.datak.2011.01.001

Rodriguez, R. R., Juan, J. A. S., \& Angel, O. B. (2009). "Quantitative Relationships between Key Performance Indicators for Supporting Decision-Making Processes," Computers in Industry, 60, 104-113. http://dx.doi.org/10.1016/j.compind.2008.09.002

Safa, M., Arash, S., Carl, T. H., \& Keith, W. H. (2014). Supplier Selection Process in an Integrated Construction Materials Management Model. Automation in Construction, 48, 64-73 http://dx.doi.org/10.1016/j.autcon.2014.08.008

Subramanian, N., \& Ramakrishnan, R. (2012). A Review of Applications of Analytic Hierarchy Process in Operations Management. International Journal of Production Economics, 215-241. http://dx.doi.org/10.1016/j.ijpe.2012.03.036

Suwignjo, P., Bititci, U. S., \& Carrie, A. S. (2000). Quantitative Models for Performance Measurement System. International Journal of Production 231-241. http://dx.doi.org/10.1016/S0925-5273(99)00061-4

Textile. (2014). Association marocaine du textiles et de. AMITH. Documentations de l'IFM (2008 - 2012), p. 2. http://www.textile.ma/portail/PageFR.aspx?id=64

Verma, R., \& Madeleine, E. P. (1998). An Analysis of the Supplier Selection Process. Omega, 739-750. http://dx.doi.org/10.1016/S0305-0483(98)00023-1

Vonderembse, M., Tracey, M., Tan, C. L., \& Bardi, E. J. (1995). Cur, Current Purchasing Practices and JIT: Some of Effects on Inbound Logistics. International Journal of Physical Distribution \& Logistics Management, 3, 33-48.

Weber, C., John, A., Current, R., \& Benton, W. C. (1991). Vendor Selection Criteria and Methods. European Journal of Operational Research, 2-18. http://dx.doi.org/10.1016/0377-2217(91)90033-R

\section{Copyrights}

Copyright for this article is retained by the author(s), with first publication rights granted to the journal.

This is an open-access article distributed under the terms and conditions of the Creative Commons Attribution license (http://creativecommons.org/licenses/by/3.0/). 